\title{
Uma investigação funcional da conjunção aunque em dados do espanhol falado peninsular
}

\section{A Functional Investigation of the Conjunction aunque in Spoken Iberian Spanish}

Sandra Denise Gasparini Bastos

Universidade Estadual Paulista (UNESP), São José do Rio Preto, São Paulo, Brasil. sandradg@ibilce.unesp.br

Beatriz Goaveia Garcia Parra

Universidade Estadual Paulista (UNESP), São José do Rio Preto, São Paulo, Brasil. biagarcia.parra@hotmail.com

Resumo: Este trabalho tem por objetivo fazer uma descrição dos elementos que caracterizam as orações concessivas introduzidas pela conjunção aunque em dados do espanhol peninsular falado. Partindo da estrutura em camadas da frase proposta por Hengeveld $(1988,1989)$ e Dik (1989), dentro de uma perspectiva funcionalista da linguagem, e da adaptação desse modelo feita por Crevels (1998, 2000a, 2000b), especificamente para as orações concessivas, verificamos que a conjunção aunque pode atuar em diferentes camadas e ainda introduzir estruturas que só podem ser descritas fora dos limites da frase.

\footnotetext{
${ }^{1}$ Bolsa de Iniciação Científica concedida pela FAPESP (Processo 2012/20765-9) para o desenvolvimento do Projeto de Pesquisa "Uma investigação funcional da conjunção 'aunque' em dados do espanhol falado peninsular” ( $1^{\circ}$ fev. 2013 a 31 dez. 2013).

Bolsa de Mestrado concedida pela CAPES para o desenvolvimento do Projeto de Pesquisa "Uma investigação discursivo-funcional das orações introduzidas por 'aunque' em dados do espanhol peninsular" (Início: 3 mar. 2014).
} 
Palavras-chave: Orações concessivas; Conjunção aunque; Gramática Funcional; Espanhol falado.

Abstract: This paper aims at describing the elements that characterize the concessive clauses introduced by "aunque" in spoken Iberian Spanish. The analysis was based on the layered structure of the clause proposed by Hengeveld $(1988,1989)$ and Dik (1989), from a functional perspective of language, and on the adaptation of this model for concessive clauses (CREVELS, 1998, 2000a, 2000b). Results showed that the conjunction "aunque" may function in different layers, introducing structures that can only be described beyond the limits of the clause.

Keywords: Concessive clauses; Conjunction aunque; Functional Grammar; Spoken Iberian Spanish.

Recebido em 01 de junho de 2014. Aprovado em 29 de outubro de 2014.

\section{Introdução}

Tradicionalmente, as orações subordinadas concessivas podem ser definidas como orações que apresentam uma objeção ou dificuldade ao que é dito na outra oração, sem que isso impeça seu cumprimento (ALARCOS LLORACH, 1999).

Quirk et al. (1985) definem um enunciado concessivo como sendo aquele que indica que a situação expressa na oração principal é contrária à expectativa gerada à luz do que é dito na oração concessiva.

Entre as conjunções e locuções concessivas comumente apresentadas pelas gramáticas normativas do espanhol, destaca-se a conjunção aunque, que, conforme apontam a Real Academia Española (1931), Alarcos Llorach (1999) e Gili Gaya (2000), é a conjunção mais utilizada para introduzir orações de sentido concessivo na língua espanhola atual. Tal conjunção, segundo Ibba (2007), não provém do latim, como ocorre com a maioria das conjunções concessivas do espanhol, mas resulta de um processo de gramaticalização.

Elvira (2005) afirma que, em razão de as conjunções concessivas serem fruto da evolução da própria língua, sua incorporação ao sistema linguístico é tardia e que tais conjunções apresentam um sentido mais 
literal e transparente do que as demais conjunções subordinativas. Além disso, a etimologia dessas conjunções é facilmente dedutível por meio de suas formas.

Considerando a importância da conjunção aunque para a produção de orações concessivas em língua espanhola, este trabalho tem por objetivo descrever, dentro de uma perspectiva funcionalista da linguagem, as orações introduzidas por essa conjunção no espanhol peninsular falado, considerando a estrutura em camadas proposta por Hengeveld $(1988,1989)$ e por Dik (1989) e a adaptação dessa estrutura especificamente para as orações concessivas proposta por Crevels (1998, 2000a, 2000b). Com o intuito de observar os elementos que caracterizam cada tipo oracional, utilizaremos como parâmetros de análise a camada de atuação da conjunção aunque e sua interação com o modo verbal, o tempo verbal e a posição da oração concessiva com relação à oração principal, elementos que se mostraram mais pertinentes para a análise.

O corpus adotado para esta investigação consiste em um conjunto de amostras de língua espanhola falada extraído do Projeto PRESEEA (Proyecto para el Estudio Sociolingüístico del Español de España y de América), coordenado pelo professor Francisco Moreno, da Universidade de Alcalá de Henares (Espanha). Tal projeto visa à criação de um corpus de língua falada que represente o mundo hispânico em sua variedade geográfica e social. Por ser um projeto amplo, o recolhimento do corpus ainda não está concluído em todos os países integrantes. Dessa forma, para o presente estudo, utilizamos as amostras correspondentes às cidades espanholas de Alcalá de Henares e de Granada, que estão na fase mais avançada do projeto, com dados já transcritos e publicados.

De cada cidade foram selecionadas 36 entrevistas, sendo 18 de cada nível de instrução (superior e secundário). Sendo assim, a amostra total utilizada para o levantamento das ocorrências contém 72 entrevistas, que, juntas, somam cerca de 50 horas de gravação.

Para cumprir o objetivo proposto, este trabalho organiza-se da seguinte maneira: no item 1, é apresentada a estrutura em camadas da frase, conforme proposta de Hengeveld (1988, 1989) e de Dik (1989); no item 2, são descritos os tipos de orações concessivas, de acordo com a classificação apresentada em Crevels (1998, 2000a, 2000b), a partir da proposta do modelo de Dik (1989); no item 3, são descritos e analisados os elementos que caracterizam as orações concessivas introduzidas pela conjunção aunque identificadas no corpus, com base nos parâmetros previamente estabelecidos. Seguem as considerações finais que permitem 
traçar um perfil desse tipo de oração e apontar caminhos que levam a investigações futuras, de forma a contribuir para com os estudos funcionalistas e os estudos descritivos do espanhol.

\section{A teoria da Gramática Funcional}

Esta pesquisa toma como base a abordagem funcional de linha holandesa desenvolvida por Dik $(1989,1997)$, denominada Gramática Funcional (GF) e que, nos moldes da Escola Linguística de Praga, trabalha com a concepção do caráter teleológico da linguagem, isto é, considera que a linguagem busca atingir uma finalidade. Para a GF, a língua é definida como um instrumento de interação social entre seres humanos, cuja principal função é estabelecer a comunicação entre seus usuários.

Hengeveld (1988, 1989) e Dik (1989) sugerem uma representação em camadas para a estrutura da frase (clause, no original em inglês). Tal construção requer um predicado, que se aplica a certo número de termos, resultando numa predicação. Os predicados designam propriedades ou relações, os termos referem-se a entidades e as predicações designam um conjunto de estados-de-coisas, definidos como algo que acontece no mundo real ou é criado no mundo mental do falante ou do ouvinte, podendo ser percebido de alguma maneira e localizado no tempo e no espaço. Como exemplo de predicado temos o verbo cantar, que ao receber marcação de tempo, configura-se como um estado-de-coisas:

\section{(1) João cantou ontem. (Camada da predicação)}

Uma predicação pode, ainda, ser construída em uma estrutura de ordem mais alta, a proposição, que designa um conteúdo proposicional ou um fato possível, isto é, um construto mental que não pode ser localizado no espaço nem no tempo, mas pode ser avaliado em termos de sua verdade, como mostra o exemplo (2), cujo conteúdo está sob o escopo do modalizador provavelmente:

(2) Provavelmente, João cantou ontem. (Camada da proposição)

Em um nível acima da proposição está a frase, que é a designação de um ato de fala especificado pela proposição e constituído de quatro componentes: uma ilocução, um falante, um ouvinte e um conteúdo comunicado, como está ilustrado em (3): 
(3) Sinceramente, não acredito que o João tenha cantado ontem. (Camada da frase)

A organização em níveis configura-se, então, da seguinte maneira:

Quadro 1 - Estrutura em camadas da frase (DIK, 1989)

\begin{tabular}{c|c|c}
\hline Unidade estrutural & Tipo de entidade & Ordem \\
\hline Frase & Ato de fala & 4 \\
\hline Proposição & Conteúdo proposicional & 3 \\
\hline Predicação & Estado-de-coisas & 2 \\
\hline Predicado & Termo & 1 \\
\hline
\end{tabular}

Crevels (1998), ao analisar orações concessivas do espanhol e ao fazer uma investigação tipológica das orações concessivas (2000a, 2000b), estabelece uma relação entre esse tipo oracional e as camadas propostas por Hengeveld $(1988,1989)$ e por Dik (1989). A autora considera que há diferentes tipos de orações concessivas - os quais podem atuar na camada da predicação, da proposição e da frase - e identifica, ainda, a existência de um tipo de oração concessiva que não se enquadra nas camadas anteriormente apresentadas. Esse tipo de oração, como veremos, não se relaciona a uma única oração anterior ou posterior, mas a todo um conjunto de enunciados precedentes, marcando, assim, uma quebra inesperada na ordem do discurso.

Como forma de contribuir com o modelo de descrição funcionalista, Crevels (1998) propõe o acréscimo de mais uma camada à estruturação elaborada por Dik (1989), a qual denomina Unidade textual. Assim, tendo em vista o acréscimo proposto pela autora, a organização das expressões linguísticas em camadas apresenta-se da seguinte forma:

Quadro 2 - Estrutura em camadas adaptada para as orações concessivas (CREVELS, 1998, p. 133)

\begin{tabular}{c|c|c}
\hline Tipo de entidade & Descrição & Avaliação \\
\hline Quinta ordem & Unidade textual & Continuidade temática \\
\hline Quarta ordem & Ato de fala & Sucesso \\
\hline Terceira ordem & Conteúdo proposicional & Verdade \\
\hline Segunda ordem & Estado-de-coisas & Realidade \\
\hline Primeira ordem & Indivíduo & Existência \\
\hline Zero ordem & Propriedade ou relação & Aplicabilidade \\
\hline
\end{tabular}




\section{A estrutura em camadas das orações concessivas introduzidas por aunque}

Considerando as características da abordagem funcionalista e o modelo de estruturação em camadas proposto por Dik (1989), complementado por Crevels (1998, 2000a, 2000b), no que diz respeito às orações concessivas, observamos que essas orações podem representar todos os tipos de entidades propostos pela Gramática Funcional, exceto as de primeira ordem (indivíduos), pois, nesse nível, a expressão só se realiza por meio de sintagmas nominais.

Dessa forma, Crevels $(1998,2000 \mathrm{a}, 2000 \mathrm{~b})$ organiza as orações concessivas em quatro domínios: o domínio do conteúdo (segunda ordem), o domínio epistêmico (terceira ordem), o domínio ilocucionário (quarta ordem) ${ }^{2}$ e o domínio textual (quinta ordem), sendo que, como afirma a autora, quanto mais alto for o domínio semântico a que uma concessiva pertence, menor será o seu grau de integração com a oração principal e mais parecida a uma estrutura paratática ela se tornará. Além disso, a autora defende que, dentro de cada domínio, podem ser encontrados diferentes subtipos de orações concessivas que manifestam distintos graus de subordinação e integração com a oração principal. Apresentaremos, na sequência, as características semânticas e sintáticas pertencentes a cada domínio semântico.

\subsection{Concessivas de domínio do conteúdo}

Segundo Crevels (1998, 2000a, 2000b), as orações concessivas de domínio do conteúdo descrevem um evento ou estado-de-coisas que configura um obstáculo para a realização do evento ou estado-decoisas descrito na oração principal, mas que não consegue impedir a ocorrência desse evento. Para Neves et al. (2008), que também fazem uma classificação das concessivas em subtipos, tendo como base o português brasileiro, nas concessivas de conteúdo ocorre a frustração de uma expectativa causal que se estabelece entre o fato expresso pela oração concessiva e o expresso pela oração principal, como podemos observar no exemplo a seguir, oferecido por Crevels (1998): ${ }^{3}$

\footnotetext{
${ }^{2}$ Também chamado de domínio dos atos de fala (CREVELS, 2000b, p. 318), esse subtipo é equivalente ao que Neves et al. (2008, p. 977) chamam de domínio conversacional. ${ }^{3}$ Todos os exemplos em espanhol serão acompanhados de sua tradução para o português.
} 
(4) Saldremos aunque llueve. (CREVELS, 1998, p. 133)

(Sairemos, embora esteja chovendo.)

Em (4), temos uma oração concessiva de domínio do conteúdo, pois o estado-de-coisas da oração concessiva (llueve) atua como um obstáculo ao estado-de-coisas expresso na oração principal (saldremos), mas a expectativa lógica (não sair em dias de chuva) é quebrada ao se confirmar a realização do evento.

\subsection{Concessivas de domínio epistêmico}

As orações concessivas de domínio epistêmico representam conteúdos proposicionais e combinam, nas estruturas das quais fazem parte, dois itens do conhecimento: uma premissa (expressa na oração subordinada) e uma conclusão conflitante (expressa na oração principal).

Como afirma Crevels (1998, 2000a, 2000b), essas construções expressam a ideia de que o falante, apesar de estar convencido do conteúdo da oração concessiva, chega a uma conclusão oposta, contida na oração principal. Em outras palavras, no domínio epistêmico, a conjunção concessiva marca o impedimento de uma crença ou de uma conclusão pressuposta. Logo, as concessivas epistêmicas não expressam um conflito factual, mas um conflito entre a conclusão e o possível contra-argumento expresso na oração concessiva. Vejamos o exemplo:

(5) Aunque no compartimos la ideología del PSOE, preferimos que estén ellos a que haya un gobierno de derechas. (CREVELS, 1998, p. 136)

(Apesar de não compartilharmos a ideologia do PSOE, preferimos eles a um governo de direita.)

Em (5), observamos que a oração subordinada traz uma premissa (no compartimos la ideología del PSOE) que nos levaria a concluir que o falante é contra um governo assumido por tal partido. No entanto, a conjunção concessiva marca o impedimento dessa conclusão pressuposta 
e o que se afirma na oração principal (preferimos que estén ellos a que haya un gobierno de derechas) é uma conclusão contrária ao que se poderia esperar a partir da premissa inicial.

\subsection{Concessivas de domínio ilocucionário}

De acordo com Crevels (2000a), a oração concessiva de domínio ilocucionário, juntamente com a principal, faz parte de uma construção única, que pode especificar ou modificar um único ato de fala precedente ou posterior. Para a autora, no domínio dos atos de fala, o conteúdo das orações concessivas não forma um obstáculo para a realização do evento ou estado-de-coisas descrito na oração principal, mas oferece um obstáculo à realização do próprio ato de fala, como observamos no exemplo (6):

(6) Aunque te llamo un poco tarde, ¿qué vas a hacer esta noche? (CREVELS, 1998, p. 133)

(Embora eu esteja te ligando um pouco tarde, o que você vai fazer esta noite?)

Conforme aponta Crevels (2000a), as orações concessivas de domínio ilocucionário também se caracterizam por apresentar atos de fala pouco informativos, como exemplifica (7):

(7) María, la carta se encuentra en el cajón - aunque estoy convencida de que ya lo sabes. (CREVELS, 1998, p. 137)

(Maria, a carta está na gaveta - embora eu esteja convencida de que você já sabe disso.)

Nesse exemplo, a oração subordinada traz um comentário que o falante se sente obrigado a fazer a respeito da violação cometida aos princípios informativos da comunicação. As circunstâncias comunicativas conduzem ao seguinte raciocínio lógico: "se eu sei que meu interlocutor está informado de que a carta está na gaveta, eu não deveria realizar um ato de fala que trouxesse tal informação." 
König (1994) identifica, dentro do grupo das construções concessivas de ato de fala, a existência de um subtipo oracional que apresenta características semânticas e sintáticas particulares: as concessivas retóricas (rhetorical concessive) que, segundo o autor, são tipicamente introduzidas por conectivos concessivos enfáticos, como o verbo modal may, em inglês, papel também desempenhado pelas conjunções concessivas although e though, que correspondem à conjunção concessiva aunque, no espanhol. Segundo o autor, as concessivas retóricas são usadas particularmente para admitir a afirmação trazida pela oração concessiva e enfatizar a informação presente na oração principal. Assim, é possível observar, nesse subtipo oracional, que o ato de fala expresso na oração concessiva adianta uma possível objeção por parte do ouvinte ao ato de fala referido na oração principal, como exemplifica (8), extraído de Crevels (1998):

Aunque no se lleva ahora decirlo, sí soy fidelista, muy fidelista. (CREVELS, 1998, p. 138)

(Embora não seja muito comum dizer isto hoje em dia, eu sou fidelista, muito fidelista [partidário de Fidel Castro].)

Observamos que em (8) o falante deseja declarar sua admiração por Fidel, mas sabe que seu ouvinte poderia rejeitar essa enunciação por considerá-la pouco adequada nos dias de hoje. Dessa forma, o falante sente a necessidade de adiantar esse possível contra-argumento por parte de seu interlocutor para expressar o ato de fala contido na oração principal.

Crevels (1998) também reconhece a existência de outro subtipo de orações concessivas de domínio ilocucionário, às quais chamou de concessivas avaliativas (evaluating concessive). As concessivas avaliativas caracterizam-se por apresentar uma avaliação, realizada pelo falante, do ato de fala presente na oração principal, ao julgar que esse ato não deveria ter sido enunciado da maneira como foi. Tais concessivas, segundo a autora, ocorrem frequentemente combinadas com expressões ou partículas enfáticas, que em espanhol podem ser representadas por $l o$ cierto es que, bien es cierto, la verdad es que, está claro que, claro, si e sobre todo, mas também podem ser introduzidas pela conjunção aunque, como demonstra o exemplo a seguir: 
(9) A: ¿Se considera la conciencia crítica de los poderes públicos y políticos?

B: Algunas veces sí, aunque la verdad es que no es exactamente así. (CREVELS, 1998, p. 138)

(A: A consciência crítica dos poderes públicos e políticos é considerada?

B: Algumas vezes sim, embora na verdade não seja exatamente assim.)

\subsection{Concessivas de domínio textual}

As orações concessivas de domínio textual correspondem às unidades textuais, entidades de quinta ordem que, como foi apresentado anteriormente, foram acrescentadas por Crevels (1998, 2000a, 2000b) ao modelo de estruturação em camadas elaborado por Dik (1989) especificamente para as orações concessivas. Segundo a autora, essas orações concessivas não formam um obstáculo à realização de uma situação descrita na oração principal, como acontece com as orações dos domínios anteriores. Elas se configuram como orações relativamente independentes, que modificam uma unidade textual precedente, composta por mais de uma oração, e excluem certa interpretação que poderia ter sido elaborada pelo ouvinte no decorrer do discurso.

Como afirma Crevels (2000a, 2000b), as concessivas textuais também se caracterizam por sinalizar um turno inesperado no contexto discursivo e auxiliar em sua organização, atuando frequentemente como adendos. Vejamos o exemplo (10):

(10) A: La suya es una vida muy intensa y dicen que es un incorregible conquistador... 
B: He vivido la vida mucho, me gusta así. Y en cuanto a eso de conquistador, tal vez lo era, pero ya... aunque la verdad es que los hombres no ligan. (CREVELS, 1998, p. 133)

(A: A sua vida é muito intensa e dizem que o senhor é um incorrigível conquistador...

B: Vivi muito a vida, eu gosto assim. E quanto a isso de conquistador, talvez fosse, mas agora... embora a verdade seja que os homens não se relacionam.)

Com base nas descrições apresentadas, podemos notar que a oração concessiva destacada no exemplo (10) atua como um turno inesperado no discurso e modifica uma série de pronunciamentos anteriores, pois, ao afirmar que os homens não se relacionam, o falante se contrapõe à ideia apresentada ao longo do discurso de que era um grande conquistador.

\section{Análise das orações concessivas introduzidas por aunque}

A partir dos níveis de atuação previstos para as orações concessivas, apresentamos, nesta seção, o resultado da análise das 211 ocorrências de orações concessivas introduzidas pela conjunção aunque identificadas no corpus. Além da camada de atuação, os resultados serão apresentados com relação aos critérios propostos para a caracterização de cada tipo oracional no âmbito deste trabalho: modo verbal, tempo verbal e posição da oração concessiva introduzida por aunque.

\subsection{Camada de ocorrência da oração concessiva}

Considerando a possibilidade de as orações concessivas atuarem na segunda, na terceira, na quarta ou na quinta camada oracional, de acordo com o modelo de estruturação proposto por Dik (1989) e adaptado por Crevels (1998, 2000a, 2000b), o número percentual de ocorrências encontradas, de acordo com o nível de atuação da conjunção, está representado na tabela a seguir: 
Tabela 1 - Ocorrências de aunque com relação à camada de atuação

\begin{tabular}{c|c|c}
\hline Camada de atuação & Ocorrências & $\mathbf{\%}$ \\
\hline Estado-de-coisas $\left(2^{\mathrm{a}}\right)$ & 36 & 17,06 \\
\hline Conteúdo proposicional $\left(3^{\mathrm{a}}\right)$ & 100 & 47,4 \\
\hline Ato de fala $\left(4^{\mathrm{a}}\right)$ & 21 & 9,95 \\
\hline Unidade textual $\left(5^{\mathrm{a}}\right)$ & 19 & 9,0 \\
\hline Orações independentes & 35 & 16,59 \\
\hline TOTAL & $\mathbf{2 1 1}$ & $\mathbf{1 0 0}$
\end{tabular}

Com base nos resultados, verificamos que a maior frequência dos casos de aunque concessivo se dá na camada do conteúdo proposicional, ${ }^{4}$ nas chamadas orações concessivas de domínio epistêmico (terceira ordem). Vejamos o exemplo:

(11) Creo que me entienden aunque parezca un niño de dos tres años. (32H-GR09) $)^{5}$

(Acho que me entendem, embora eu pareça uma criança de dois ou três anos.)

Como se nota no exemplo, a relação estabelecida entre oração principal e concessiva não se dá entre fatos ou eventos do mundo, mas entre processos mentais ou raciocínios do falante, o que corrobora a hipótese formulada por Neves et al. (2008, p. 977) para o português de que "as construções concessivas são usadas principalmente para negar conclusões possíveis a partir de premissas oferecidas previamente."

A segunda camada com maior número de ocorrências é a do estado-de-coisas (segunda ordem), que, nos termos de Crevels (1998), corresponde às orações concessivas que pertencem ao domínio do conteúdo. Vejamos o exemplo:

\footnotetext{
${ }^{4}$ Resultado semelhante é verificado por Neves et al. (2008) nas orações concessivas do português brasileiro.

${ }^{5}$ A notação referente ao corpus deve ser interpretada da seguinte maneira: número do informante, sexo do informante $(\mathrm{H}=$ homem ou $\mathrm{M}=$ mulher), sigla da cidade ( $\mathrm{GR}=$ Granada ou $\mathrm{AH}=$ Alcalá de Henares $)$ e número da amostra.
} 
(12) Las leyes aquí se aplican tarde y mal prácticamente no se aplican aunque están en vigor. (33H-GR13)

(As leis aqui se aplicam tarde e mal; praticamente não se aplicam apesar de estarem em vigor.)

No exemplo (12), o fato expresso pela oração subordinada - aunque están en vigor - cria um obstáculo real que não logra impedir a realização do evento expresso na oração principal - las leyes aqui se aplican tarde y mal.

$\mathrm{O}$ terceiro tipo oracional mais frequente introduzido por aunque está representado pelas orações que correspondem a atos de fala (camada ilocucionária), chamadas de concessivas de domínio ilocucionário. Observemos o exemplo (13):

(13) Un poco los españoles salimos un poquito perjudica(d)os aunque parezca un poco pedante decirlo. (33M-GR17)

(Os espanhóis saímos um pouquinho prejudicados, embora pareça um pouco pedante dizer isso.)

Nesse exemplo, a oração introduzida por aunque forma um obstáculo à realização do ato de fala expresso na oração anterior; nesse caso, o fato de parecer pedante poderia impedir o falante de dizer que os espanhóis saíram um pouco prejudicados na situação descrita.

A ocorrência de orações de quinta ordem nos dados analisados, apesar de pouco frequente, contribui para demonstrar a viabilidade do acréscimo proposto por Crevels ao modelo inicial da Gramática Funcional de linha holandesa. Vejamos o exemplo:

(14) La enseñanza puedo decir que que para mí ahora mismo es un callejón sin salida no a mí me ha gusta(d)o mucho pero tal como la la veo y la estoy viviendo y lo que me está tocando padecer pues no realmente me es un peso no no no es una fuente de disfrute aunque lógicamente hay cursos y situaciones que son agradables y que son buenas pero que pesa mucho (32MGR12) 
(O ensino, posso dizer que para mim é uma rua sem saída. Eu já gostei muito, mas tal como o vejo hoje e o estou vivendo e o que estou padecendo, realmente é um peso, não é uma fonte de desfrute, embora logicamente haja cursos e situações que sejam agradáveis e que sejam bons, mas que pesam muito)

O exemplo (14) equivale a uma concessiva de domínio textual, uma vez que a oração em destaque não se opõe a uma única oração, mas ao conjunto de orações anteriores, atuando como uma ressalva e evitando, dessa forma, uma interpretação equivocada por parte do falante. Nesse enunciado, o falante apresenta, ao longo de sua intervenção, um posicionamento negativo a respeito do ensino, mas reconhece, mediante o uso da oração introduzida por aunque, que pode haver cursos e situações agradáveis.

Além das orações que correspondem às camadas oracionais anteriormente previstas, identificamos, na análise dos dados, estruturas oracionais introduzidas por aunque que não se enquadram exatamente em nenhum dos domínios propostos. Assim como as estruturas pertencentes à quinta camada, essas orações, que aparecem em 16,98\% das ocorrências, não apresentam uma oração principal com a qual possam estabelecer uma oposição bimembre. Entretanto, diferentemente das concessivas de unidade textual, que atuam como um adendo a um conjunto de pronunciamentos anteriores ao intervir de forma inesperada no andamento do discurso, as orações pertencentes a esse novo grupo marcam o início de um novo movimento discursivo, como podemos verificar nos exemplos que seguem:

(15) Sigue habiéndola actualmente una máquina pensada para el desayuno que le das a un botón y sale pues zumo de naranja aunque en realidad son polvos color naranja mezclado con agua zumo de limón o zumo de piña. (31M-GR06)

(Atualmente existe uma máquina pensada para o café da manhã que você aperta um botão e sai suco de laranja, embora na realidade seja pó cor de laranja misturado com água, suco de limão ou suco de abacaxi.) 
(16) Después de estar nueve años con una persona que más o menos aunque el matrimonio no es lo mismo que un noviazgo pero que sí si ya tienes mucha más confianza conoces a la persona sabes cómo es sabes... en fin. (32H-GR32)

(Depois de estar nove anos com uma pessoa que mais ou menos... embora o casamento não seja o mesmo que um noivado, mas sim se você já tem mais confiança, conhece a pessoa, sabe como ela é, sabe... enfim.)

No exemplo (15), o falante interrompe a explicação sobre o funcionamento de uma máquina de fazer sucos para dizer que o líquido produzido por essas máquinas não é propriamente suco de laranja, mas sim pó cor de laranja misturado com água. No exemplo (16), o falante faz um parêntese para comentar que casamento não é o mesmo que noivado.

Decat (1999), ao estudar as orações subordinadas no português, chamou de orações desgarradas o tipo oracional presente em (15) e em (16), pois, segundo a autora, a relação entre orações dessa natureza caminha para uma independência, originando, assim, orações que não estão estruturalmente integradas com outras. O papel desempenhado por essas orações seria, portanto, atuar na organização do discurso.

Garcia (2010), ao estudar as orações concessivas no português falado, encontrou orações do mesmo tipo, às quais chamou de orações independentes, caracterizadas como sendo um comentário do falante com relação ao conteúdo apresentado, configurando, assim, uma unidade de informação à parte.

Do mesmo modo, consideramos que as orações destacadas nos exemplos (15) e (16), que também chamaremos de orações independentes, não estabelecem relações sintáticas com as orações anteriores nem com as posteriores, mas assumem a forma de um parêntese, isto é, de uma inserção provocada pelo falante que gera um breve desvio do tópico discursivo que vinha sendo desenvolvido. Para Garcia (2010), a relação existente nessas orações é pragmática e interpessoal, uma vez que o falante só as enuncia por considerar pertinente que o ouvinte conheça o conteúdo comunicado na oração concessiva.

Neste trabalho, não nos deteremos na descrição desse tipo oracional, uma vez que a teoria gramatical aqui adotada não abrange 
os níveis de análise em que essas orações atuam. Mas propomos que tais orações possam ser descritas com base em um modelo mais amplo de interação verbal, que ultrapasse o nível da frase e alcance o nível do discurso, como, por exemplo, a teoria da Gramática Discursivo-Funcional (GDF), proposta por Hengeveld e Mackenzie (2008).

A GDF é atualmente concebida como um modelo de interação verbal que se distingue de outras teorias de análise linguística por apresentar uma arquitetura descendente (top-down), isto é, organizada em níveis e em camadas hierarquicamente dispostos, que partem da intenção comunicativa do falante e vão até a articulação das formas linguísticas. Na organização interna da GDF, a pragmática governa a semântica, que, juntas, governam a morfossintaxe. E a pragmática, a semântica e a morfossintaxe, por sua vez, governam a fonologia. Com base nesse modelo de análise, as concessivas independentes poderiam ser descritas como pertencentes ao Nível Interpessoal, descrito na teoria como o nível das relações pragmáticas, e atuariam na camada do Movimento (Move), uma vez que constituem, segundo Garcia (2010), uma ação ou um movimento para introduzir ou modificar tópicos discursivos que levam a interação adiante. ${ }^{6}$

A partir das descrições sobre as camadas de atuação das orações concessivas iniciadas por aunque, apresentaremos, nos próximos itens, os resultados advindos da relação estabelecida entre a camada oracional e os demais parâmetros de análise.

\subsection{Modo verbal da oração concessiva}

Com relação ao modo do verbo da oração subordinada concessiva em espanhol, a Real Academia Española (1931) e gramáticos como Matte Bon (1995) e Gili Gaya (2000) afirmam que as orações concessivas introduzidas por aunque podem apresentar verbos tanto no modo indicativo como no modo subjuntivo. Esse emprego, contudo, não é facultativo, pois, segundo Gili Gaya (2000), a subordinada concessiva com verbo no indicativo demonstra a existência efetiva de um obstáculo ao cumprimento do que foi enunciado na oração principal, enquanto a oração concessiva com verbo no subjuntivo indica que a dificuldade

\footnotetext{
${ }^{6}$ Outro exemplo de análise baseada na descrição das orações subordinadas independentes à luz da Gramática Discursivo-Funcional pode ser visto em Stassi-Sé (2012).
} 
expressa pela subordinada representa um obstáculo hipotético, de realização possível, mas não comprovada.

De Kock (1995) explica que as gramáticas da língua espanhola postulam uma teoria dicotômica sobre o uso dos modos verbais nas orações concessivas, segundo a qual o indicativo é destinado à expressão de fatos reais e o subjuntivo à expressão de hipóteses. No entanto, para o autor, em uma situação real de comunicação, é possível verificar casos que não seguem a regra tradicionalmente prevista, como, por exemplo, a utilização do modo subjuntivo em subordinadas concessivas que transmitem um fato real.

Ao estudar um corpus formado por dados do espanhol falado e escrito de diversos países que têm esse idioma como língua oficial, De Kock (1995) verificou que, no espanhol falado culto de algumas cidades como Madri, por exemplo, todas as orações concessivas que apresentavam um obstáculo hipotético traziam o verbo no modo subjuntivo, enquanto as concessivas que expressavam um obstáculo real ora traziam o verbo no indicativo, ora no subjuntivo. Comportamento semelhante foi verificado pelo autor no espanhol escrito peninsular.

A respeito do uso dos modos verbais nas orações concessivas do espanhol, Rivas (1990) ressalta que, na evolução da língua, houve a anulação de um processo de oposição mais produtivo (uso de indicativo para orações reais e de subjuntivo para orações não reais) e manteve-se a possibilidade de uso dos dois modos verbais em razão de vantagens pragmáticas e estilísticas.

Tendo em vista os casos de subjuntivo em orações concessivas que expressam conteúdos reais, podemos hipotetizar que o uso do modo verbal nas orações concessivas introduzidas por aunque não dependerá somente do grau de certeza, isto é, de realidade que está contido em tais construções. Dessa forma, é possível acreditar que o verbo da oração subordinada é utilizado no modo indicativo quando o falante confere ao enunciado concessivo, além do grau de [+certeza], o grau de [+novidade] e [+importância], isto é, quando o falante julga que a informação contida naquela oração é de possível ou de real ocorrência, é desconhecida pelo seu interlocutor, ou que seu conhecimento é relevante para o ouvinte. Já o modo subjuntivo é utilizado quando o falante confere à oração concessiva os graus de [-certeza], [-novidade] ou [-importância], isto é, quando o falante julga que a informação trazida pela oração subordinada possui pouca probabilidade de ocorrência ou é hipotética, já é conhecida por seu interlocutor, ou que sua enunciação não é relevante para o ouvinte. 
Nos dados analisados, considerando o número total de ocorrências introduzidas por aunque concessivo, é possível dizer que, nessas orações, predomina o uso do modo subjuntivo $(51,19 \%$ das ocorrências) frente ao modo indicativo $(48,81 \%)$, embora a diferença seja relativamente pequena. Da relação estabelecida entre a camada de atuação da conjunção aunque com o modo verbal, temos os seguintes resultados:

Tabela 2 - Modo verbal das orações concessivas com relação à camada de

\begin{tabular}{c|c|c|c|c}
\multicolumn{4}{c}{ atuação } \\
\hline Camada de atuação & \multicolumn{2}{|c|}{ Indicativo } & \multicolumn{2}{c}{ Subjuntivo } \\
\hline & $\mathbf{N}^{\circ}$ & $\mathbf{\%}$ & $\mathbf{N}^{\circ}$ & $\mathbf{\%}$ \\
\hline Estado-de-coisas $\left(2^{\mathrm{a}}\right)$ & 9 & 4,27 & 27 & 12,8 \\
\hline Conteúdo proposicional $\left(3^{\mathrm{a}}\right)$ & 42 & 19,9 & 58 & 27,49 \\
\hline Ato de fala $\left(4^{\mathrm{a}}\right)$ & 11 & 5,21 & 10 & 4,74 \\
\hline Unidade textual $\left(5^{\mathrm{a}}\right)$ & 17 & 8,06 & 2 & 0,95 \\
\hline Orações independentes & 24 & 11,37 & 11 & 5,21 \\
\hline TOTAL & $\mathbf{1 0 3}$ & $\mathbf{4 8 , 8 1}$ & $\mathbf{1 0 8}$ & $\mathbf{5 1 , 1 9}$ \\
\hline
\end{tabular}

Vemos, na TAB. 2, que o modo subjuntivo predomina nas orações pertencentes às camadas do estado-de-coisas e do conteúdo proposicional, isto é, nas camadas mais baixas de atuação, que correspondem às orações mais dependentes sintaticamente da oração principal, como demonstram, respectivamente, os exemplos (17) e (18):

(17) Porque mi padre no freía un huevo aunque se muriera de hambre. (H31-AH7)

(Porque meu pai não fritava um ovo, ainda que morresse de fome.)

(18) Es tu personalidad así aunque creas que no. (M24-AH2)

(A sua personalidade é assim, embora você ache que não.)

Já o modo indicativo é mais frequente nas camadas mais altas, isto é, nas que codificam ato de fala e unidade textual, bem como nas orações 
aqui denominadas independentes, como demonstram, respectivamente, os exemplos (19) e (20):

(19) Pues porque se estudiaba más en el colegio te tenían más vigilado y bueno aunque era siempre más caro que lo oficial pero los padres se preocupan de que los hijos estén lo mejor posible. (H33-AH2)

(Porque se estudava mais no colégio, te vigiavam mais, e ainda que fosse mais caro que o oficial, mas os pais se preocupam que os filhos estejam o melhor possível.)

(20) También el Vaticano sí si lo vimos más tranquilo fue una mañana aunque fue rápido también con la guía pero nos tocó una guía fue muy buena. (22H-GR26)

(O Vaticano também nós vimos mais tranquilamente, foi uma manhã, embora tenha sido rápido também com a guia, tivemos uma guia muito boa.)

Podemos observar, por meio dos exemplos, que o modo subjuntivo é usado nas orações concessivas quando a informação enunciada corresponde a uma hipótese, como observamos em (17) e em (18), em que os conteúdos "morrer de fome" e "acreditar em algo" não são reais, mas sim pressupostos pelo falante. Conforme previsto, o emprego do subjuntivo também para eventos reais é possível, como demonstra o exemplo (21):

(21) Normalmente utilizo el coche aunque no esté lejos el lugar de trabajo. (33M-GR17)

(Normalmente uso o carro, embora meu local de trabalho não esteja longe.) 
Nesse exemplo, o falante não tem dúvidas quanto ao seu local de trabalho, apresentado como não distante de sua casa. Essa informação real admitiria o emprego do modo indicativo em espanhol (aunque no está lejos el lugar de trabajo), substituído, nesse contexto, pelo subjuntivo para dar um caráter mais subjetivo à informação, o que pode justificar o número relativamente maior de ocorrências do modo subjuntivo frente ao modo indicativo.

Já o indicativo em contexto concessivo configura informações reais, isto é, as afirmações de que o colégio era caro e de que o passeio ao Vaticano foi rápido - exemplos (19) e (20) - são situações cujas ocorrências podem ser comprovadas no mundo real.

\subsection{Tempo verbal da oração concessiva}

Com relação ao tempo verbal das orações concessivas introduzidas pela conjunção aunque, hipotetizamos a possibilidade de ocorrência do presente e do passado, já que o futuro não parece ser um tempo verbal característico desse tipo de oração. A distribuição das ocorrências entre os tempos verbais mostra um expressivo predomínio do presente $(77,25 \%$ do total de ocorrências), seguido de $22,28 \%$ de ocorrências do passado. Identificamos, ainda, uma única ocorrência de futuro (0,47\% do total), conforme se pode observar na tabela a seguir:

Tabela 3 - Tempo verbal das orações concessivas com relação à camada de atuação

\begin{tabular}{c|c|c|c|c|c|c}
\hline Camada de atuação & \multicolumn{2}{|c|}{ Passado } & \multicolumn{2}{c|}{ Presente } & \multicolumn{2}{c}{ Futuro } \\
\hline & $\mathbf{N}^{\circ}$ & $\mathbf{\%}$ & $\mathbf{N}^{\circ}$ & $\mathbf{\%}$ & $\mathbf{N}^{\circ}$ & $\mathbf{\%}$ \\
\hline Estado-de-coisas $\left(2^{\mathrm{a}}\right)$ & 6 & 2,85 & 30 & 14,21 & \multicolumn{2}{|c}{----} \\
\hline Conteúdo proposicional $\left(3^{\mathrm{a}}\right)$ & 23 & 10,9 & 77 & 36,5 & \multicolumn{3}{|c}{----} \\
\hline Ato de fala $\left(4^{\mathrm{a}}\right)$ & 2 & 0,94 & 19 & 9,0 & \multicolumn{3}{|c}{----} \\
\hline Unidade textual $\left(5^{\mathrm{a}}\right)$ & 6 & 2,85 & 12 & 5,69 & 1 & 0,47 \\
\hline Orações independentes & 10 & 4,74 & 25 & 11,85 & \multicolumn{2}{|c|}{---} \\
\hline TOTAL & $\mathbf{4 7}$ & $\mathbf{2 2 , 2 8}$ & $\mathbf{1 6 3}$ & $\mathbf{7 7 , 2 5}$ & $\mathbf{1}$ & $\mathbf{0 , 4 7}$ \\
\hline
\end{tabular}

De uma maneira geral, os verbos da oração subordinada introduzida por aunque aparecem majoritariamente no tempo presente, seguido do passado e com apenas uma ocorrência no futuro, o que confirma a hipótese inicial para o emprego dos tempos verbais. O presente do subjuntivo foi a relação modo-temporal mais frequente nos dados analisados, conforme ilustram os exemplos (22), (23), (24) e (25), 
equivalentes, respectivamente, a um estado-de-coisas, a um conteúdo proposicional, a um ato ilocucionário e a uma unidade textual:

(22) Indudablemente hay que ser agradable aunque un día te levantes que te duelen las muelas. (22H-GR27)

(Sem dúvida é necessário ser agradável, mesmo que um dia você se levante com dor de dente.)

(23) Yo en el campo me sentiría mucho más atada que en la ciudad aunque los espacios sean más libres. (32M-GR11)

(Eu no campo me sentiria muito mais presa do que na cidade, embora os espaços sejam mais livres.)

(24) Lo de la cocina tiene su envergadura aunque tú digas que no (33M-GR17)

(O assunto da cozinha tem a sua importância, embora você diga que não.)

(25) Por lo menos es mi filosofía ¿no? el hacer lo que me gusta y enriquecerme como persona ¿no? aunque luego el bolsillo se queje ¿no? (H20-AH2)

(Pelo menos é minha filosofia, né? Fazer o que eu gosto e enriquecer-me como pessoa, né? Embora depois o bolso reclame, né?)

Quando consideramos as camadas de atuação da conjunção aunque, o predomínio do presente do subjuntivo se mostra mais frequente nas orações de segunda e de terceira ordem (estados-de-coisas 
e conteúdos proposicionais, respectivamente), enquanto nas demais predomina o presente do indicativo. A alta frequência do presente do subjuntivo está relacionada ao fato de que ele expressa também valores futuros. Se considerarmos, por exemplo, a ocorrência (22), vemos que sua tradução para o português poderia levar ao emprego do futuro do subjuntivo ("mesmo que um dia você se levantar com dor de dente"), tempo verbal em desuso no espanhol contemporâneo, frequentemente substituído pelo presente do subjuntivo.

No que diz respeito ao uso do tempo futuro, não é possível fazer afirmações mais precisas, visto que apenas uma ocorrência foi identificada no corpus (concessiva de unidade textual). Se tomarmos essa ocorrência, ilustrada a seguir, como referência, podemos pensar que o emprego do futuro pode estar limitado às camadas mais altas e às orações que apresentem mais independência com relação a uma oração principal, mas essa afirmação carece de mais dados.

(26) Es otro mundo es otra mentalidad y la sociedad lo que es aquí urbana pues es muy muy diferente es todo muy estresante es no hay ese sol que hay en el campo no hay ese verde la lo que es la gente en sí como la manera que se cría también aunque bueno habrá también gente humilde. (12M-GR23)

(É outro mundo, é outra mentalidade e a sociedade que aqui é urbana é muito diferente, é tudo muito estressante e não tem esse sol que tem no campo, não tem esse verde, o que são as pessoas em si mesmas, a maneira de se criar, embora haja gente humilde também.)

Em (26), podemos notar que o futuro é utilizado, assim como os tempos do subjuntivo, para indicar uma situação hipotética, geralmente sentida pelo falante como pouco comum ou de difícil realização. Dessa forma, o fato de existirem pessoas humildes na cidade pode acontecer, mas isso não é visto como algo comum para o falante.

Quanto às orações aqui tratadas como independentes, por não apresentarem relação explícita com a oração anterior nem com a posterior, o tempo verbal predominante é o presente do indicativo, tempo menos marcado, diretamente relacionado com o caráter mais independente desse 
subtipo oracional, como vemos no exemplo (27), em que a informação dada pelo informante de que não se importa com o fato de não se sair bem na cozinha (la cocina es lo que peor llevo aunque me da igual) aparece como uma espécie de parêntese:

(27) Pero lo que es la cocina es lo que peor llevo aunque me da igual yo no sé hacer un plato y digo "pues esto tiene que llevar esto esto y esto" y yo sola me lo ingenio ahí para hacerlo hago mis propias recetas. (12M-GR24)

(Mas a cozinha é o que pior faço, embora não me importe, eu não sei fazer um prato e digo "nisso tem que colocar isso isso e isso" e eu sozinha encontro meios para fazê-lo, faço minhas próprias receitas.)

O emprego do passado também é comum nesse grupo de orações, como mostra o exemplo (20), aqui repetido por conveniência em (28):

(28) También el Vaticano sí si lo vimos más tranquilo fue una mañana aunque fue rápido también con la guía pero nos tocó una guía fue muy buena. (22H-GR26)

(O Vaticano também nós vimos mais tranquilamente, foi uma manhã, embora tenha sido rápido também com a guia, tivemos uma guia muito boa.)

Tanto nas orações concessivas independentes que trazem o verbo no presente como nas que trazem o verbo no passado, identifica-se um valor de comentário ou de parêntese que permite ao falante fazer uma espécie de desvio do texto original para depois retomá-lo na sequência.

\subsection{Posição da oração concessiva com relação à principal}

Sobre a posição ocupada pela oração concessiva iniciada por aunque, consideramos que essas orações podem vir antepostas ou pospostas à oração principal - tomando-se o verbo como referência - a depender das estratégias argumentativas do falante e do tipo de informação a ser enunciada. 
Flamenco García (2000) argumenta que quando o falante antepõe a oração concessiva iniciada por aunque à oração principal, sua intenção comunicativa é polemizar acerca de um discurso previamente emitido ou simplesmente pressuposto por seu interlocutor. Assim, a conjunção introduz uma informação temática, ou seja, já conhecida pelos interlocutores. Por outro lado, quando o falante pospõe a oração concessiva, seu objetivo é o de adiantar e rejeitar uma possível objeção do ouvinte. Nesse caso, a informação introduzida pela conjunção é nova ou remática.

Ainda a respeito da posição das orações concessivas com relação à principal, Neves (1999) argumenta que as orações concessivas antepostas carregam a informação mais conhecida pelo interlocutor, ocupando, por isso, uma posição mais tópica. Para a autora, as concessivas pospostas ora atuam como ressalva a um ponto particular do enunciado, ora como um comentário por meio do qual "o locutor acrescenta outros conteúdos ou argumentos a um segmento linguístico aparentemente concluído" (NEVES et al., 2008, p. 982). Observemos os exemplos (29) e (30):

(29) Yo prefiero vivir en la ciudad aunque ahora mismo el centro está imposible. (32M-GR12)

(Eu prefiro viver na cidade, embora agora o centro esteja impossível.)

(30) E: Y viendo su afición al té ¿ha ido a las teterías?

I: Bueno aunque tome té a la a esta hora del desayuno por la mañana y a veces por la tarde no significa que yo tenga afición al té. (33H-GR15)

(E: E vendo seu gosto por chá, o senhor foi às casas de chá?

I: Bom, embora eu tome chá na hora do café da manhã e às vezes à tarde, não significa que eu seja viciado em chá.) 
Em (29), observamos que a oração concessiva ocupa a posição posposta à oração principal e introduz uma informação nova no discurso (ahora mismo el centro está imposible). A função argumentativa da oração concessiva posposta é, segundo Flamenco García (2000), adiantar um possível contra-argumento do ouvinte, que poderia ser formulado a partir da informação anterior, expressa na oração principal.

Já no exemplo (30), vemos que a oração concessiva está anteposta à oração principal. Tal posição justifica-se pelo fato de que a informação por ela codificada já é conhecida pelos interlocutores. Assim, a intenção argumentativa do falante ao produzir o enunciado concessivo é de polemizar a respeito da informação dada pelo contexto comunicativo e compartilhada pela informação pragmática dos participantes que, no caso do exemplo em análise, corresponde ao fato de que o entrevistado toma chá frequentemente.

$\mathrm{Na}$ análise da posição ocupada pela oração concessiva introduzida por aunque não foram consideradas as 35 ocorrências que se enquadram nas orações aqui tratadas como independentes, uma vez que tais orações não estabelecem relações sintáticas com os enunciados anteriores nem posteriores. Por essa razão, o número total considerado para esse critério foi de 176 ocorrências. Verificamos que a posição posposta $(59,1 \%$ das ocorrências) predomina sobre a anteposta $(40,9 \%)$, como mostra a tabela a seguir:

Tabela 4 - Posição das orações concessivas com relação à camada de atuação

\begin{tabular}{c|c|c|c|c}
\hline Camada de atuação & \multicolumn{2}{|c|}{ Posposição } & \multicolumn{2}{c}{ Anteposição } \\
\hline & $\mathbf{N}^{\circ}$ & $\mathbf{\%}$ & $\mathbf{N}^{\circ}$ & $\mathbf{\%}$ \\
\hline Estado-de-coisas $\left(2^{\mathrm{a}}\right)$ & 34 & 19,32 & 2 & 1,13 \\
\hline Conteúdo proposicional $\left(3^{\mathrm{a}}\right)$ & 41 & 23,3 & 59 & 33,52 \\
\hline Ato de fala $\left(4^{\mathrm{a}}\right)$ & 10 & 5,68 & 11 & 6,25 \\
\hline Unidade textual $\left(5^{\mathrm{a}}\right)$ & 19 & 10,8 & \multicolumn{2}{|c}{$-\mathrm{-I}^{-}$} \\
\hline TOTAL & $\mathbf{1 0 4}$ & $\mathbf{5 9 , 1}$ & $\mathbf{7 2}$ & $\mathbf{4 0 , 9}$ \\
\hline
\end{tabular}

Considerando as camadas de atuação da conjunção aunque, os dados comprovam que nas orações de segunda ordem (estado-de-coisas), a posição posposta é mais frequente, como mostra o exemplo a seguir:

(31) Porque la ciudad te acoge aunque sea de gran tamaño. (32MGR11) 
(Porque a cidade te acolhe ainda que seja grande.)

Tal resultado corrobora a posição de Crevels (2000a), que, ao descrever as características das concessivas de domínio do conteúdo, afirma ser a posposição um traço que as diferencia das demais concessivas. Orações concessivas de segunda ordem antepostas à oração principal são muito raras e podem ser visualizadas no exemplo a seguir:

(32) aunque se lavaban los puestos por la noche a la hora de la verbena aquello olía a pesca(d)o. (33H-GR15)

(Embora lavassem os postos à noite na hora da festa, aquilo cheirava a peixe.)

As orações concessivas que representam conteúdos proposicionais e atos de fala, por sua vez, tendem a ocorrer antepostas à oração principal, embora a diferença no caso das orações de domínio ilocucionário entre anteposição e posposição seja pouco representativa. Os exemplos (33) e (34) ilustram, respectivamente, orações de domínio epistêmico e de domínio ilocucionário:

(33) Aunque [el pueblo] era pequeño hacían unas fiestas mu(y) bonitas. (33M-GR16)

(Embora o povoado fosse pequeno, faziam umas festas muito bonitas.)

(34) Aunque no estés de acuerdo dices "esto es lo que hay esto es lo que hay". (22H-GR25)

(Embora você não esteja de acordo, diz "é o que tem, é o que tem".) 
As orações concessivas que representam unidades textuais, por sua configuração específica de comentário, só podem aparecer em posição posposta, como se observa no exemplo (35):

(35) es verdad que cuando te mueves en un círculo pues los amigos son de ese círculo eso es evidente y por eso los reyes se van con reyes y los pobres se van con pobres eso es lo normal y además creo que eso no: por lo menos aquí en España no va a cambiar así como así y sobre todo en ciudades como Alcalá menos porque en Alcalá sí que esta gente es de los de Alcalá de toda la vida: este no: aunque ya ha cambiado todo eso por los institutos y eso [...] (H15- AH3)

(É verdade que quando você se move em um círculo, os amigos são desse círculo, isso é evidente, e por isso os reis vão com os reis e os pobres vão com os pobres, isso é normal; além disso, acho que isso não, pelo menos aqui na Espanha, não vai mudar sem mais nem menos e em cidades como Alcalá menos ainda, porque em Alcalá sim que tem gente de Alcalá de toda a vida e gente que não, embora já tenha mudado tudo isso por causa dos institutos e tal [...])

Com base nas discussões apresentadas e tendo em vista as posições que predominam em cada camada de atuação, podemos concluir que as concessivas de segunda e de quinta ordem tendem a introduzir uma informação nova no discurso e a estratégia argumentativa da qual fazem parte é de evitar possíveis contra-argumentos do ouvinte ou interpretações equivocadas do que foi dito antes. Sendo assim, a concessiva aunque sea de gran tamaño, em (31), impede que o ouvinte utilize esse argumento para tentar invalidar o que é afirmado na oração principal. Também a oração aunque ya ha cambiado todo eso por los institutos y eso, em (35), funciona como uma espécie de ressalva que tenta evitar que o ouvinte tire conclusões equivocadas a partir do que foi dito antes, que poderia levá-lo à conclusão de que na cidade de Alcalá de Henares o comportamento social não muda.

Já as orações de terceira e de quarta ordem tendem, por sua vez, a acompanhar uma informação já conhecida pelos interlocutores e demonstrar que, embora haja o conhecimento do que nelas se afirma, 
isso não impede a conclusão apresentada na oração principal. Assim, desde o início, o falante já apresenta o argumento da oração concessiva como sendo um obstáculo falho, pois ao enunciar aunque [el pueblo] era pequeño, como no exemplo (33), tal informação já é sentida como insuficiente para impedir que se conclua que as festas eram bonitas. Da mesma forma, a concessiva aunque no estés de acuerdo, em (34), é incapaz de impedir a enunciação do ato de fala principal (dices esto es lo que hay esto es lo que hay).

\section{Considerações finais}

Este trabalho teve por objetivo fazer uma descrição dos elementos que caracterizam as orações concessivas introduzidas pela conjunção aunque, em dados do espanhol falado peninsular pertencentes ao Projeto PRESEEA. Como parâmetros de análise que nos apoiaram nessa descrição, consideramos a camada de atuação da conjunção aunque, o modo verbal, o tempo verbal e a posição da oração concessiva com relação ao verbo da oração principal.

À estrutura em camadas da frase proposta por Hengeveld (1988, 1989) e por Dik (1989), que permite separar diferentes unidades introduzidas pela conjunção aunque, consideramos o acréscimo de uma quinta camada, sugerido por Crevels (1998, 2000a, 2000b) especificamente para o caso das orações concessivas. Assim, verificamos, inicialmente, que as orações concessivas introduzidas pela conjunção aunque em espanhol podem pertencer a quatro grupos diferentes, considerando sua camada de atuação: orações de segunda ordem ou concessivas de domínio de conteúdo; orações de terceira ordem ou concessivas de domínio epistêmico; orações de quarta ordem ou concessivas de domínio ilocucionário; e orações de quinta ordem ou concessivas de unidade textual.

Além dos tipos inicialmente previstos, verificamos, na análise dos dados, a existência de um grupo diferenciado de orações introduzidas pela conjunção aunque que não se encaixa em nenhuma das categorias propostas, uma vez que não estabelece uma relação clara com as orações anteriores ou posteriores. Tratamos essas orações como as chamadas orações independentes descritas por Garcia (2010) e por Stassi-Sé (2012) no âmbito da Gramática Discursivo-Funcional. Dada a impossibilidade de analisarmos esse grupo oracional dentro de uma teoria que se limita 
à extensão da frase, propomos que sua descrição seja feita com base numa teoria que considere estruturas que ultrapassem os limites da frase, como a Teoria da Gramática Discursivo-Funcional (HENGEVELD; MACKENZIE, 2008), teoria ainda em desenvolvimento, que representa uma evolução da Gramática Funcional de Dik (1989, 1997).

$\mathrm{Na}$ análise das ocorrências de orações introduzidas por aunque nos dados do corpus, verificamos que tais orações representam majoritariamente conteúdos proposicionais, isto é, atuam na camada da proposição, conforme proposta de Dik (1989), equivalendo a concessivas de domínio epistêmico. Esse tipo oracional apresenta o verbo predominantemente no modo subjuntivo (presente) e ocorre com mais frequência em posição posposta com relação ao verbo da oração principal.

Ao descrevermos as características sintático-semânticas que pertencem aos demais tipos oracionais introduzidos por aunque, observamos que as orações de segunda ordem ou concessivas de domínio de conteúdo, segundo tipo mais frequente no corpus, são marcadas pelo predomínio do presente do modo subjuntivo e caracterizadas pela posição posposta, confirmando a descrição de Crevels (2000a).

Nas orações concessivas que ocupam camadas mais altas, como as concessivas de domínio ilocucionário e as concessivas de unidade textual, predomina o presente do modo indicativo. As concessivas de domínio ilocucionário parecem apresentar certa liberdade posicional, pois o número de ocorrências de orações antepostas e pospostas foi praticamente idêntico. Já as orações que representam unidades textuais, por seu caráter de adendo ou comentário, aparecem categoricamente na posição posposta.

Com relação ao modo, verificamos que, em números reais, o emprego do subjuntivo foi ligeiramente maior do que o emprego do indicativo, embora a diferença não tenha sido tão representativa. $\mathrm{O}$ predomínio do subjuntivo nas orações que ocupam camadas mais baixas e do indicativo nas orações que ocupam camadas mais altas permitenos comprovar que o modo subjuntivo está relacionado às orações que são sintaticamente mais dependentes da oração principal, enquanto o modo indicativo é mais frequente em estruturas que apresentam certa independência sintática.

Quanto ao tempo verbal, em todos os tipos oracionais, o emprego mais frequente foi o do presente. Houve maior frequência de presente do subjuntivo nas orações de segunda e de terceira ordem e de presente 
do indicativo nas orações que ocupam as camadas mais altas. A alta frequência do presente, em especial do presente do subjuntivo, justifica-se em grande parte em razão do desaparecimento do futuro do subjuntivo no espanhol contemporâneo e sua substituição por outros tempos verbais, como o presente do subjuntivo no caso das orações concessivas.

Com relação à posição, verificamos que as orações concessivas de segunda ordem tendem a aparecer pospostas porque geralmente introduzem uma informação nova no discurso, servindo como uma estratégia do falante para evitar possíveis contra-argumentos do ouvinte ou interpretações equivocadas do que foi expresso na oração principal. Comportamento semelhante apresentam as orações de quinta ordem (unidade textual), que só podem aparecer pospostas. As orações de terceira e de quarta ordem, por sua vez, tendem a aparecer antepostas, apresentando um obstáculo falho no impedimento da realização do evento descrito na oração principal.

Tendo em vista a análise aqui empreendida, esperamos ter contribuído para a descrição das orações concessivas introduzidas por aunque no espanhol peninsular falado e para os estudos funcionalistas de uma maneira geral, especialmente os que envolvem a descrição do espanhol.

\section{Referências}

ALARCOS LLORACH, E. Gramática de la Lengua Española. Madrid: Espasa, 1999.

CREVELS, M. Concession in Spanish. In: HANNAY, M.; BOLKESTEIN, A. M. (Eds.). Functional Grammar and Verbal Interaction. Amsterdam; Philadelphia: John Benjamins Publishing Company, 1998. v. 44, p. 129-148.

CREVELS, M. Concession: A Typological Study. 2000. 191 f. Tese (Doutorado) - University of Amsterdam, Amsterdam, 2000a.

CREVELS, M. Concessives on Different Semantic Levels: A Typological Perspective. In: COUPERKUHLEN, E.; KORTMANN, B. (Ed.). Cause, Condition, Concession, Contrast Cognitive and Discourse Perspectives. Berlin: Mouton de Gruyter, 2000b. p. 313-339.

DECAT, M. B. Por uma abordagem da (in)dependência de cláusulas à luz da noção de "unidade informacional". Scripta, Belo Horizonte, v. 2, n. 4, p. 23-38, jan.-jun. 1999.

DE KOCK, J. Aunque con indicativo o subjuntivo en España y América, en español escrito y hablado. Lenguaje y Textos, Valencia, n. 6-7, p. 145$160,1995$. 
DIK, S. The Theory of Funcional Grammar. Dordrecht: Foris, 1989. v. 1. DIK, S. The Theory of Functional Grammar. In: HENGEVELD, K. (Ed.). Berlin; New York: Mouton de Gruyter, 1997. v. 2.

ELVIRA, J. Metonímia y enriquecimiento pragmático: a propósito de "aunque". Dicenda. Cuadernos de Filología Hispánica, Madrid, n. 23, p. 71-84, 2005.

FLAMENCO GARCÍA, L. Las construcciones concesivas y adversativas. In: BOSQUE, I.; DEMONTE, V. (Org.). Gramática descriptiva de la lengua española. Madrid: Espasa-Calpe, 2000. v. 3: Entre la oración y el discurso, p. 3805-3878.

GARCIA, T. S. As relações concessivas no português falado sob a perspectiva da Gramática Discursivo-Funcional. 2010. 176 f. Tese (Doutorado em Linguística) - Instituto de Biociências, Letras e Ciências Exatas, Universidade Estadual Paulista, São José do Rio Preto, 2010.

GILI GAYA, S. Curso superior de sintaxis española. 15. ed. Barcelona: Vox, 2000.

HENGEVELD, K. Illocution, Mood and Modality in a Functional Grammar of Spanish. Journal of Semantics, n. 6, p. 227-269, 1988.

HENGEVELD, K. Layers and Operators in Functional Grammar. Journal of Linguistics, n. 25, p. 127-157, 1989.

HENGEVELD, K.; MACKENZIE, L. Functional Discourse Grammar. Oxford (UK): Oxford University Press, 2008.

IBBA, D. Oraciones concesivas y gramaticalización: el caso de aunque y maguer (que). Intralingüistica, n. 17, p. 493-502, 2007. Disponível em: $<$ http://dialnet.unirioja.es/servlet/articulo? codigo $=2317374>$. Acesso em: 23 mar. 2013.

KÖNIG, E. Concessive Clauses. In: ASHER, R. E. (Ed.). The Encyclopedia of Language and Linguistics. v. 2. Oxford: Pergamon, 1994. p. 679-681.

MATTE BON, F. Gramática comunicativa del español. Madrid: Edelsa, 1995. t. 2.

NEVES, M. H. M. As construções concessivas. In: . (Org.). Gramática do português falado. São Paulo: Humanitas/FFLCH/USP; Campinas: Editora da UNICAMP, 1999. v. 7: Novos estudos, p. 545-591. 
NEVES, M. H. M. et al. As construções hipotáticas. In: ILARI, R.; NEVES, M. H. M (Org.). Gramática do português culto falado no Brasil. Campinas: Editora da UNICAMP, 2008. v. 2: Classes de palavras e processos de construção, p. 937-1015.

QUIRK, R. et al. A Comprehensive Grammar of the English Language. London: Longman, 1985.

REAL ACADEMIA ESPAÑOLA. Gramática de la Lengua Española. Madrid: Espasa-Calpe, 1931. p. 396-401.

RIVAS, E. A propósito de condicionales y concesivas reales: referencias diacrónicas en torno a estas últimas. Verba, n. 17. p. 159-169, 1990.

STASSI-SÉ, J. C. Subordinação discursiva no português à luz da gramática discursivo-funcional. 2012. 194 f. Tese (Doutorado em Linguística) - Instituto de Biociências, Letras e Ciências Exatas, Universidade Estadual Paulista, São José do Rio Preto, 2012. 